\title{
Analysis of Facial Image Extraction on Facial Recognition using Kohonen SOM for UNPRI SIAKAD Online User Authentication
}

\author{
Reyhan Achmad Rizal \\ University of Prima Indonesia \\ Medan, University of Prima Indonesia \\ reyhanachmadrizal@unprimdn.ac.id
}

\author{
Christnatalis HS \\ Prima Indonesia University \\ Medan, Prima Indonesia University \\ christnatalis@ unprimdn.ac.id
}

\begin{abstract}
Academic Information System (Sistem Informasi Akademik aka SIAKAD) Online of Universitas Prima Indonesia (UNPRI) is one of the applications used to facilitate the administration process of lectures which includes the filling process of study plan cards (Kartu Rencana Studi aka KRS), study result cards (Kartu Hasil Studi aka KHS), class schedules, submission of research titles, seminars, and other processes. SIAKAD UNPRI can be accessed by students, lecturers and academics where every user has a password that has been encrypted to maintain the security of information from people who are not responsible, password security using the encryption method needs to be changed regularly, but there are still many students, lecturers and academic community who are reluctant to change passwords. To improve the security verification stage for SIAKAD users, we propose a face recognition feature approach. Face recognition is a feature that allows the identification of someone from a digital image or video. The way facial recognition method works is by comparing face data from the camera or images with images that were previously stored in a database. In this study the Kohonen SOM method is proposed for face identification based on feature extraction approach of discrete cosine transform (DCT), linear discriminant analysis (LDA) and principal component analysis (PCA) to improve the security of UNPRI SIAKAD users. The analytical framework is done by requiring students to do face taking, where each student will save 5 (five) faces extracted with facial features using the DCT, LDA and PCA model approach, feature extraction results are used as input to the Kohonen SOM network for training and testing facial recognition, then analysis of the effect of DCT, LDA and PCA feature extraction on the Kohonen network on facial recognition accuracy.

Keywords- Facial Recognition, Kohonen SOM, discrete cosine transform (DCT), linear discriminant analysis (LDA), principal component analysis (PCA).
\end{abstract}

\section{INTRODUCTION}

Universitas Prima Indonesia (UNPRI) is one of the universities in Medan, North Sumatra Province, with 10 (ten) faculties. At present UNPRI's student administration management has implemented an Academic Administration System (Sistem Administrasi Akademik aka SIAKAD) which can be used by students to carry out the process of submitting KRS, KHS and others. Every student has a username and password that can be used to access the SIAKAD system, technically the security of the
SIAKAD system user is by applying a good password encoding, but some students are still reluctant to make changes to the password periodically, so it is likely that other students use a password. In addition, if the right of access as an administration is misused by an unauthorized person, it will have fatal consequences. In this study it is proposed to increase the user verification stage of the SIAKAD system by applying face recognition.

Face recognition feature is a feature that allows the identification of someone from a digital 
image or video. This feature is based on the ability to recognize a person's face by mapping the various characteristics of a face. Face recognition is one of the fields of research that can be applied in various fields such as identity authentication, access control, computer human interaction, commercial and law enforcement (Husein, AM, et all, 2018), this is because each face has its own characteristics that distinguish one with other.

Based on the results of several studies, this study proposes the Kohonen SOM method for face identification based on the results of facial feature extraction of the DCT, LDA and PCA methods, and then the effect of the feature extraction method on the identification accuracy level will be analyzed.

\section{Literature REVIEW}

Some researchers propose face recognition as a security system such as, (Wati DA, \& Abadianto, D, 2017) applying face identification and recognition for smart home security, (Susanto, B M., Purnomo, F E., Fahmi, F, 2017) for door security, (Gunawan, T G., et all, 2017) conducted research on the development of face recognition for smart home security, (Othman, NA \& Aydin, Im 2018) proposed face recognition with Internet of Things for smart home security applications and city.

In general there are two approaches to face recognition, which are feature-based and globally (Husein, A M., \& Harahap, M., 2017). The featurebased approach is generally processed by taking a set of features from images (nose, eyes and others) to be classified, while the global approach uses all images as patterns to be classified, but is very sensitive to image variations so it requires high computational time for identification. Neural Network (NN) method, Kohonen SOM, back-propagation (Harahap, M., Husein, A. M., Dharma, A, 2017) was proposed by many researchers for face identification. Kohonen SOM is one of the unsupervised network methods in which a self-organizing process starts with random selection of node weights on the kohonen's layer, SOM has proven to be accurate in recognizing facial patterns, but Kohonen SOM has the disadvantage of the need for large training data and high computational time. Discrete cosine transform (DCT), linear discriminant analysis (LDA), principal component analysis (PCA) methods are proven to be used for extracting facial features, so as to reduce the computational time of facial identification (Husein, AM \& Harahap, M, 2017).
The self-organizing map (SOM) technique, first introduced by Teuvo Kohonen in 1982, is a process of unsupervised learning (learning directed) learning that studies the distribution of patterns of patterns without class information (Kohonen, 2001). The SOM technique has proven useful in many applications. SOM is used for data clustering without knowing the membership class of the inputted data. SOM can be used to detect features inherent to this problem called SOFM (Self-Organizing Feature Map). The SOM architecture consists of 1 input layer and 1 output layer. Each unit in the input layer is connected to all units in the output layer with a weight connected $\mathrm{w}_{\mathrm{ij}}$.

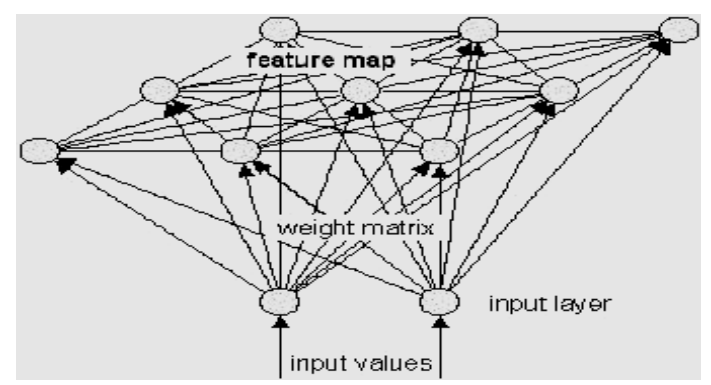

Fig. 1 Kohonen SOM Architecture

Learning Algorithm

Step 0:

- $\quad$ Initialize $\mathrm{w}_{\mathrm{ij}}$ weights.

- $\quad$ Set topological neighborhood parameters

- Set learning rate parameters

Step 1: If the stop conditions are not met (False), do steps $2-8$

Step 2: For each x vector input, work steps 3 - 5

Step 3: For each index j, calculate the value:

$$
D(j)=\sum_{i}\left(w_{i j}-x_{i}\right)^{2}
$$

Step 4: Look for the winning unit (index $J$ ), which is the unit that has the minimum D (j).

Step 5: Calculate all values $w_{i j}$ (new) with the value $j$ from step 4

$$
w_{i j}(\text { new })=w_{i j}(\text { old })+\alpha\left\lfloor x_{i}-w_{i j}(\text { old })\right\rfloor
$$

Step 6: Update the value of the learning rate.

Step 7: Reduce the distance of the neighbor (R).

Step 8: Check the stop requirements

\section{Introduction Algorithm}

Step 0: Set the value of the weight $\mathrm{w}_{\mathrm{ij}}$ (take from learning results)

Step 1: For each index $\mathrm{j}$, calculate the value: 


$$
D(j)=\sum_{i}\left(w_{i j}-x_{i}\right)^{2}
$$

Step 2: Find the winning unit (index J), i.e. the unit which has a minimum $\mathrm{D}(\mathrm{j})$.

\section{Proposed Method}

a. Research Stages

This research stage is the steps that will be carried out in solving the problem that will be discussed. Broadly speaking, the overall stages of the study are shown in Figure 2

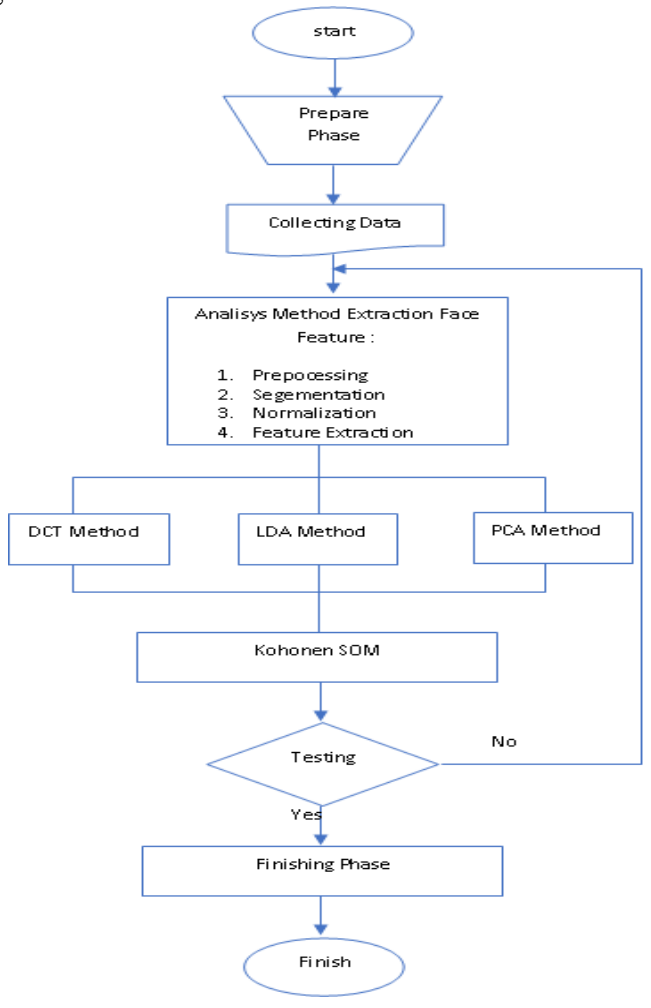

Fig. 2 Research Flow Chart

1. Preparation stage. Research activities are focused on the study of literature, enrichment of content and research context, and field surveys. From this stage the preliminary data were obtained, namely the process of entering the face image data for 2 nd and 4th semester students in the Faculty of Technology and Computer Science (Fakultas Teknologi dan Ilmu Komputer aka FTIK) of UNPRI.

2. Data Collection

At this stage there will be a process of collecting student face image data using grouping with the aim of facilitating the process of data analysis, training and method testing.

3. Design Stages. At this stage the system design is carried out including:

a. Preprocessing (cropping and scaling) is needed because each face image does not have exactly the same both in location and size so it needs to be uniformed.

b. Segmentation aims to separate between objects foreground with background.

c. Image Normalization to use the entire range of values so that a sharper image is obtained.

4. Image Feature Extraction Stages, at this stage using 3 (three) approaches, namely:

a. Discrete Cosine Transform (DCT)

b. Linear Discriminant Analysis (LDA)

c. Principal Component Analysis (PCA)

5. Implementation and Testing Phase. This stage is intended as a step to test the performance of the application program by implementing the Kohonen SOM method.

6. Stage of completion. The stage in which the activity notes and research results are documented.

b. Proposed method

This study uses a different approach to optimize PCA weaknesses by applying LDA / KDA, the class results are used as Kohonen SOM input parameters for direct multi-face classification. With the model framework as in Figure 3 below.

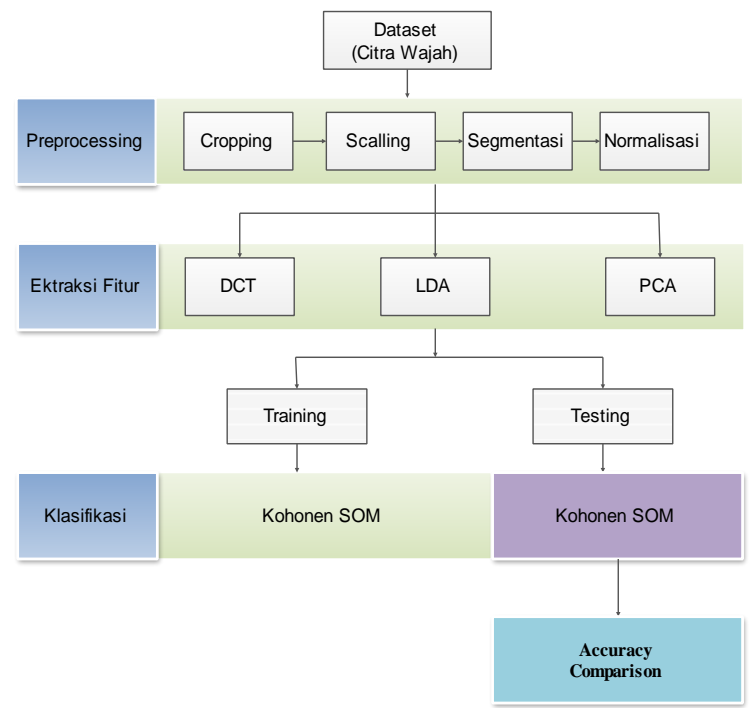

Fig. 3 Proposed Framework 


\section{Sin Journal of Publications \& Informatics Engineering Research \\ Volume 4, Number 1, October 2019 \\ DOI: https://doi.org/10.33395/sinkron.v4i1.10242

\section{RESULT AND DISCUSSION}

Experiment was carried out with Intel Core i5 $2.5 \mathrm{GHz}$ CPU, $8 \mathrm{~Gb}$ RAM and using the WIN 1064 bits operating system, the application was created using C\# 2010 with a combination of the Accord.NET framework which is a development of the framework AForge.Net. For multi-face recognition testing, the first stage is the face taking process for training. Face retrieval using a webcam then enter the name of the face image, the system will divide the face, by applying two facial feature extraction approaches, the first stage is the combination of DC, PCA and LDA, the results of the two approaches are applied to the Kohonen SOM classification method, to do the most accurate comparison analysis to identify and optimize the face extraction time. The two extraction methods will be used as Kohonen SOM input parameters by determining the threshold value $\theta=0.5$. Learning rate used is $\alpha=0.3$. The initial weight chosen is $w 1=0.01$ and $\mathrm{w} 2=0.02$. Maximum epoh $=50$, error value is obtained from the value of $t-y$. This artificial neural network training serves to teach existing facial patterns so that the network is expected to recognize new patterns. In Fig 4 an example of taking a facial image training.

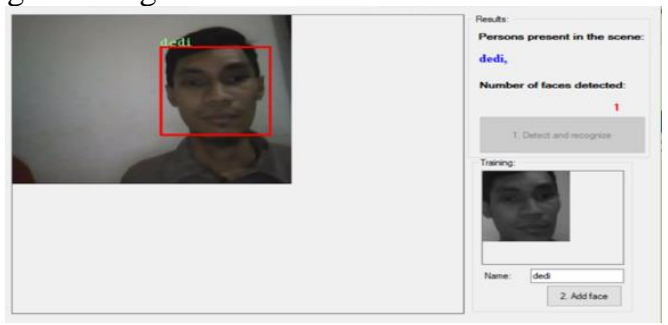

Fig. 4 Input of Training Image

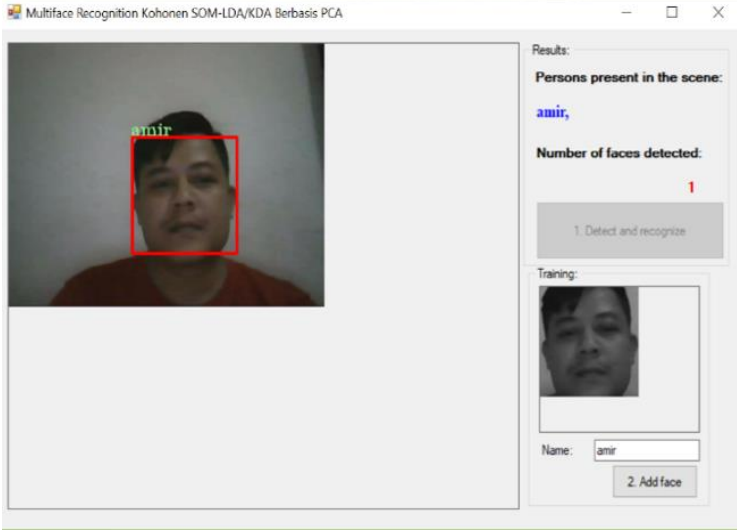

Fig. 5 Face Taking and Training

In figure 5 above, facial data trained for 20 facial images with each face taken 5 different position images, so that the total face training data for 100 face images to be trained while at the test stage used 10 face images with 3 face images each taken, the test results are displayed in figure 6

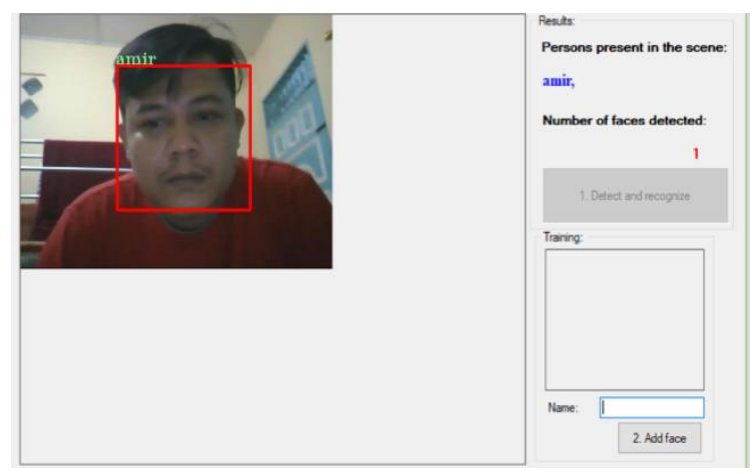

Fig. 6 Face Recognition Testing

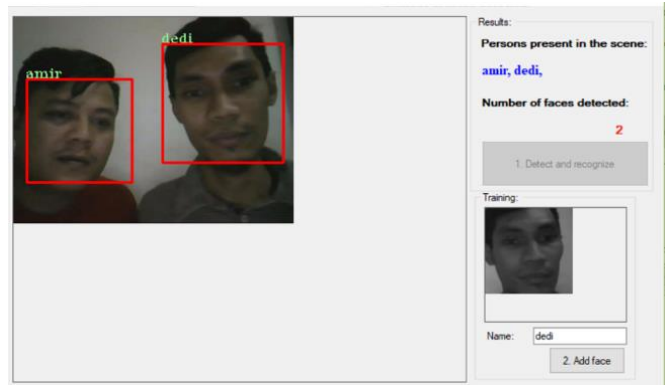

Fig. 7 Multi Face Recognition

In figure 7, multi face testing is carried out directly on applications built using DC, PCA and LDA extraction approach based on Kohonen SOM classification. The results of testing two facial extraction approaches for time accuracy and identification of the Kohonen SOM classification method. Face testing with the two approaches we applied for face and multi-face recognition, the results of the two tests were different, where at the time of multi-face testing the two approaches were less significant than the one-face testing. For more details one-face test results can be seen in table 1 and table 2 multi-face test results. Table 1 shows the face test results with a total of 10 with each of 3 facial images taken for testing with the number of iterations 5 , threshold $\theta=0.5$ Learning rate used is $\alpha=0.3$. The initial weight chosen is $\mathrm{w} 1=0.01$ and $\mathrm{w} 2=0.02$. Maximum epoh $=50$. The test results there are differences in the value of identification accuracy and time of the facial image feature extraction approach using the DC, PCA and LDA methods. the PCAKohonen combination is more accurate for classification with an average accuracy value of $95.30 \%$, while the LDA-Kohonen time accuracy is faster by 0,54 seconds for face classification.. 
Table 1. Results of Facial Classification

\begin{tabular}{|c|c|c|c|c|}
\hline \multirow[b]{2}{*}{ No } & \multirow[b]{2}{*}{ Face } & \multicolumn{3}{|c|}{ Accuracy } \\
\hline & & $\begin{array}{c}\text { DCT- } \\
\text { Kohonen }\end{array}$ & $\begin{array}{c}\text { LDA- } \\
\text { Kohonen }\end{array}$ & $\begin{array}{c}\text { PCA- } \\
\text { Kohonen }\end{array}$ \\
\hline 1 & face 1 & 93.00 & 90.00 & 95.00 \\
\hline 2 & face 2 & 89.00 & 94.00 & 96.00 \\
\hline 3 & face 3 & 90.00 & 93.00 & 97.00 \\
\hline 4 & face 4 & 94.00 & 95.00 & 93.00 \\
\hline 5 & face 5 & 92.00 & 95.00 & 95.00 \\
\hline 6 & face 6 & 90.00 & 93.00 & 96.00 \\
\hline 7 & face 7 & 91.00 & 96.00 & 94.00 \\
\hline 8 & face 8 & 89.00 & 96.00 & 95.00 \\
\hline 9 & face 9 & 92.00 & 93.00 & 97.00 \\
\hline & $\ldots$ & 93.00 & 95.00 & 95.00 \\
\hline
\end{tabular}

\section{Accuracy}

\subsection{0 \\ 95.00 \\ 90.00 \\ 85.00

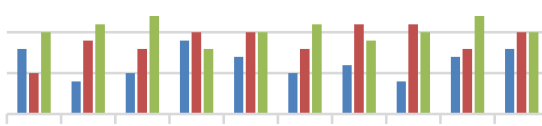 \\ facefacefacefacefacefacefacefaceface ...

$$
\begin{array}{lllllllll}
1 & 2 & 3 & 4 & 5 & 6 & 7 & 8 & 9
\end{array}
$$

- DCT-Kohonen $\square$ LDA-Kohonen $\square$ PCA-Kohonen

Fig. 7 Graph of Classification Accuracy

Table 2. Results of Multi-Face Classification

\begin{tabular}{|c|c|c|c|c|}
\hline \multirow[b]{2}{*}{ No } & \multirow[b]{2}{*}{ Face } & \multicolumn{3}{|c|}{ Time (t) } \\
\hline & & $\begin{array}{c}\text { DCT- } \\
\text { Kohonen }\end{array}$ & $\begin{array}{c}\text { LDA- } \\
\text { Kohonen }\end{array}$ & $\begin{array}{c}\text { PCA- } \\
\text { Kohonen }\end{array}$ \\
\hline 1 & face 1 & 0.34 & 0.54 & 0.86 \\
\hline 2 & face 2 & 0.99 & 0.72 & 0.58 \\
\hline 3 & face 3 & 0.09 & 0.06 & 0.70 \\
\hline 4 & face 4 & 0.83 & 0.04 & 0.92 \\
\hline 5 & face 5 & 0.96 & 0.64 & 0.39 \\
\hline 6 & face 6 & 0.94 & 0.87 & 0.71 \\
\hline 7 & face 7 & 0.32 & 0.71 & 0.52 \\
\hline 8 & face 8 & 0.80 & 0.34 & 0.15 \\
\hline 9 & face 9 & 0.13 & 0.90 & 0.49 \\
\hline .. & $\ldots$ & 0.18 & 0.53 & 0.52 \\
\hline
\end{tabular}

\section{Time $(\mathrm{t})$ \\ 1.50 \\ 1.00 \\ 0.50 \\ ה \\ face face face face face face face face face ... \\ $\begin{array}{lllllllll}1 & 2 & 3 & 4 & 5 & 6 & 7 & 8 & 9\end{array}$

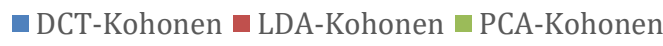

Fig. 8 Time Accuracy Graph

Table 1 shows the accuracy of the face results based on the Kohonen SOM classification using the DC, LDA and PCA extraction methods. the approach using PCA image extraction on the Kohonen SOM network resulted in a higher accuracy rate of $95.50 \&$, LDA-Kohonen $94.00 \%$ while DCKohonen was $91.30 \%$, but for face classification process time, the LDA-Kohonen combination was faster with 0.54 seconds, DC- Kohonen 0.56 seconds and PCA-Kohonen 0.58 seconds.

\section{v. CONCLUSION AND SUGgeSTION}

This study applies several methods of facial image extraction on the Kohonen SOM network to authenticate academic system security, based on the results of testing the face classification accuracy of 95.30\% on the combination of PCA-Kohonen, LDAKohonen $94 \%$ and DC-Kohonen $91.30 \%$, but for the accuracy of classification time LDA-Kohonen combination is faster than the DC and PCA extraction methods..

\section{ACKNOWLEDGMENT}

Thank you to:

1. Kemenristekdikti who has provided assistance in the form of financial support.

2. Universitas Prima Indonesia, which has provided motivational support and facilities.

\section{REFERENCES}

Wijaya, B. A., Husein, A. M., Harahap, M., \& Harahap, M. K. 2017, Implementation Distance Transform Method in Kernel Discriminant Analysis for Face Recognition Using Kohonen SOM. INTERNATIONAL JOURNAL OF ENGINEERING RESEARCH \& TECHNOLOGY (IJERT) Volume 06, Issue 10 (October 2017).

Purwanto, P., Dirgantoro, B., Jati, A N., 2015, Implementation of Face Identification and 
Face Recognition in Surveillance Cameras as Danger Detectors, e-Proceeding of Engineering: Vol.2, No.1, pp 718-724 .

Putri, M H., Putra, A B., Gaffar, A F., 2017, Feature Extraction of Human Face Images Using the Mean Absolute Error (MAE) and Discrete Cosine Transfers (DCT) Method in the Classification of Human Age, Proceedings of the 4th National Seminar on Technology, eISSN: 2598-7429, pp 28-30.

Wati, D A., Abadianto, D., 2017, Design of Face Detection and Recognition System for Smart Home Security Applications, 2nd International Conferences on Information Technology, Information Systems and Electrical Engineering (ICITISEE), pp 342347.

Wang, P., Lin, W., Chao, K., Lo, C., 2017, A FaceRecognition Approach Using Deep Reinforcement Learning Approach for User Authentication, The Fourteenth IEEE International Conference on e-Business Engineering, pp. 183- 188.

Gunawan, T S., Gani H H., Rahman, F D., Kartiwi, M., 2017, Development of Face Recognition on Raspberry Pi for Security Enhancement of Smart Home Systems, IJEEI Vol. 5, No. 4, pp 317-325.

Husein, A. M., \& Harahap, M. 2017, Penerapan Metode Distance Transform Pada Kernel Discriminant Analysis Untuk Pengenalan Pola Tulisan Tangan Angka Berbasis Principal Component Analysis. SinkrOn, 2(2), 31-36.

Harahap, M., Husein, A. M., \& Dharma, A. 2017, IDENTIFIKASI TANDA TANGAN
DENGAN KOHONEN SOM BERBASIS PRINCIPAL COMPONENT ANALYSIS.

Susanto, B M., Purnomo, F E., M. Fahmi, F I., 2017, Security System Based On Face Recognition Using Fisherface Method, Scientific Journal of INOVATION, Vol. 17 No. 1, pp. 43-47.

Bakshi, N., Prabhu, V., 2017, Face Recognition System for Access Control using Principal Component Analysis, International Conference on Intelligent Communication and Computational Techniques (ICCT), pp. 145150.

Husein, A M., Harahap, M., 2017, Multi-Face Recognition Based on Kohonen SOM Classification Optimized with the PCA Discriminant Analysis Algorithm, QUERY: Journal of Information Systems Volume: 01, Number: 02, October 2017 ISSN 2579-5341 (online), online pp 33-39.

Kurniasih, M., Akbar, S., 2018, Identification of Face Similarities for Employee Attendance Using Eigenface Algorithms, Journal of Information Technology, Vol. XIII Number 2 July 2018, ISSN: 1907-2430, pp 78-84.

Lin, W., Wu, B., Huang, Q., 2018, A FaceRecognition Approach based on Secret Sharing for User Authentication in PublicTransportation Security, Proceedings of IEEE International Conference on Applied System Innovation, IEEE ICASI, pp 1350 -1353.

Othman, N A., Aydin, I., 2018, A Face Recognition Method in the Internet of Things for Security Applications in Smart Homes and Cities, International Istanbul Smart Grids and Cities Congress and Fair (ICSG), pp. 20-24. 